\title{
Shift Schedule of Automatic Transmission of Construction Vehicle Based on Matlab/Simulink
}

\author{
Guan Liangjie $^{\mathrm{a}}$,Zhang Tiezhu $^{\mathrm{b}}$, Ma Yongzhi ${ }^{\mathrm{c}}$ \\ School of Qing Dao University, Qingdao 266071,China. \\ a248520876@qq.com,,13808995906@163.com,,'qdmayongzhi@163.com.
}

Keywords:Engineering Vehicle;Automatic Transmission;high efficiency and energy saving shift schedule.

\begin{abstract}
Aimed at the problem of engineering vehicle hydraulic mechanical transmission system efficiency is low.Thispaper mainly study of the engineering vehicle automatic transmission shift schedule.Through the artificial set the minimum numerical efficiency,this paper obtained the automatic transmission shift schedule,changed the output of the torque converter speed;And through the establishment of Matlab/Simulink based simulation system,this paper simulated and validated the process of vehicle automatic transmission.Even in the case of the speed change,the transmission of the vehicle can be through the shift operation to keep the turbine to maintain high power output,and can control the transmission efficiency of the vehicle torque converter in the relative ideal range.The study provides a theoretical basis for energy saving transformation of the domestic engineering vehicle.
\end{abstract}

\section{Introduction}

In industrial production, scrapers and loaders and other engineering vehicles often used.But once take excessive load of engineering vehicles, vehicle torque converter transmission efficiency will decrease continuously, and lead to a lot of energy waste ${ }^{[1]}$.So,through the use of automatic transmission of high efficiency and energy saving shift schedule for vehicle the efficiency of the torque converter drive control, so as to improve the performance and fuel economy of construction vehicle, and to promote the stable development of industry economy and realize the energy saving of construction vehicle has the vital significance.In order to satisfy different working conditions to shift schedule of requirements of engineering vehicles, shifting controller can automatically complete the shift schedule to the variety of the storage and can provide convenience for the driver's shift operation ${ }^{[2,3]}$.

\section{Construction vehicle automatic transmission of high efficiency and energy saving shift schedule}

The high efficiency and energy saving shift schedule. By the figure of a hydraulic torque converter of the original characteristic curves, the ideal state of vehicle transmission efficiency may reach 0.75 ,according to the numerical can determine the scope of the transmission ratio of the vehicle ${ }^{[4]}$.Specifically, in the original characteristic curves of hydraulic torque converter, there are two point, according to these two points $\eta_{\mathrm{w} 1}=\eta_{\mathrm{w} 2}=0.75$ can be according to the change of efficiency to the operation condition of the torque converter is divided into three regions, respectively, high speed than inefficient zone,low speed than inefficient zone and high efficient area. 


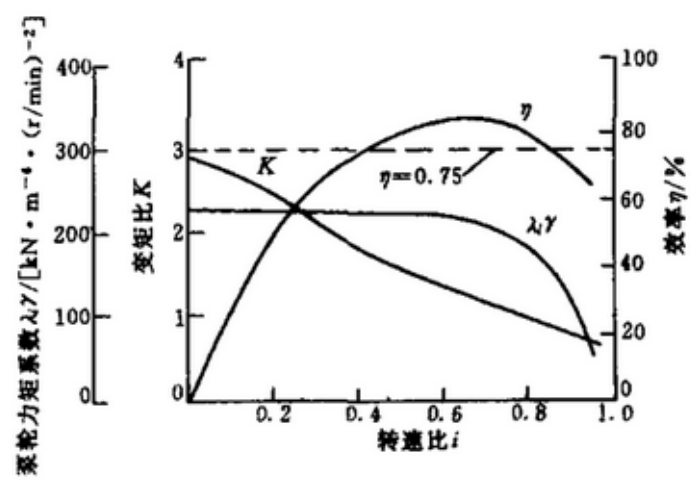

Fig. 1 Hydraulic torque converter original characteristic curve

Through the analysis found that the transmission shift in order to make the hydraulic torque converter is the purpose of the work from inefficient state into a highly efficient working condition.To make the efficiency of torque converter drive to maintain efficient by controlling the energy saving of the automatic transmission shift schedule change torque output speed ${ }^{[5]}$.

Shift principle. According to the transmission of energy saving shift schedule can know, the efficiency of hydraulic torque converter needs to be controlled within a certain range, to complete the smooth switch gear.In the vehicle model is established on the basis of research on the transmission of energy shift principle.Considering the vehicles in the working condition of inefficient area, respectively set the vehicle before and after shifting point, and guarantee the efficiency of vehicles after the shift to the left shift boundary value.So when calculating the vehicle gear transmission ratio of the next moment,need to be on the basis of the current output torque, and then complete the data transmission torque zoom in or out ${ }^{[6]}$.

Shift control. To control the vehicle automatic transmission shift schedule, need to analyze the vehicle's transmission model of the throttle and the load change on the influence of the shift.Analysis of $100 \%$ transmission output curve can be found under the throttle opening,need for power line intersects the gear shift points,to ensure that the vehicle power output.And in other under the throttle opening, can be measured by the throttle opening,vehicle pump wheel speed and turbine speed vehicle shift schedule.

Shift cycle analysis. Normally, the transmission ratio of gearbox is continuous values, measurement of transmission ratio is discrete values.And according to the sampling time to determine the number of gear, gear operation can be determined the number of half of determining the number of gear shift operation requirements for cyclic shift ${ }^{[7]}$.Once the judge circular shift transmission requirements of automatic transmission, can not the current shift required processing, and continue to complete the next shift for judgment.

\section{High efficiency and energy saving of construction vehicle automatic transmission shift schedule simulation research}

The analysis model. In order to study the efficiency of automatic transmission shift schedule of construction vehicle,and by the engine, automatic transmission and torque converter as the research object of vehicle transmission system model, and based on the system of equivalent conversion method to determine the modeling assumptions, so as to complete the simulation study of vehicle transmission shift schedule.The system output shaft between the gearbox output shaft parameters or variables,and then get the corresponding dynamic simulation model, such as type (1),(2).

$$
\begin{aligned}
& J_{e} \omega_{e}=T_{e}-T_{B} \\
& J_{t} \omega_{t}=T_{W}-M
\end{aligned}
$$

Type, $T_{\varepsilon}$ for effective torque, $\mathrm{J}_{\varepsilon}$ for between engine and torque converter turn the equivalent moment of inertia, $T_{B}$ for the torque converter input shaft torque, $T_{W}$ for transformation of the gearbox output shaft torque, $\mathrm{J}_{\mathrm{t}}$ for the turbine and the gearbox output shaft between the equivalent moment of inertia, $M$ for the gearbox output shaft torque, $\omega_{\varepsilon}$ for $J_{e}$ rotation angular velocity, $\omega_{t}$ for $J_{t}$ rotation angular velocity. 
The simulation analysis. Through the shift process of automatic transmission in Matlab/Simulink simulation, validation of high efficiency and energy saving construction vehicle automatic transmission shift schedule is correct.Under the condition of $100 \%$ throttle opening experiment, engine pump wheel and turbine initial speed, respectively $2100 \mathrm{r} / \mathrm{min}$ and $900 \mathrm{r} / \mathrm{min}$, and the vehicle gear in 1 file, and then to shift up the process of simulation, simulation results shift up process as shown in figure 2 .
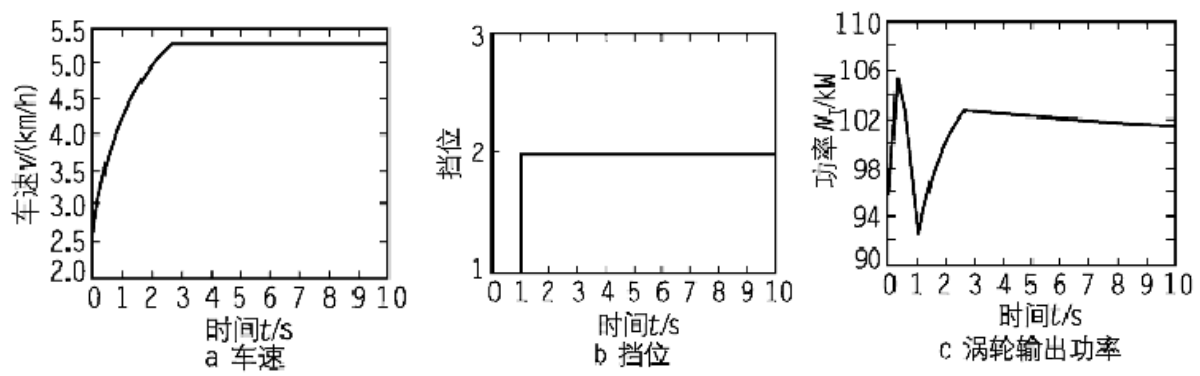

Fig. 2 The simulation results shift up process
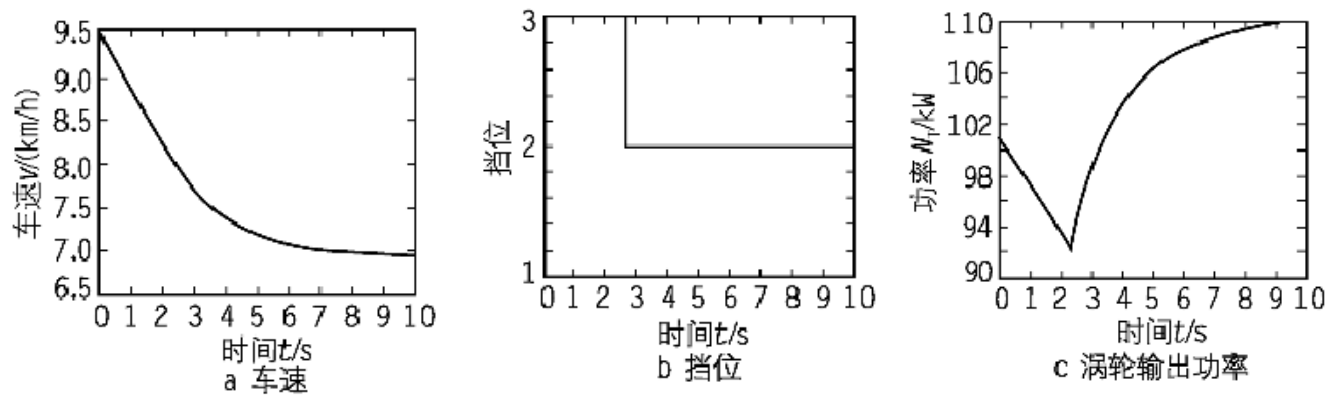

Fig.3 downshifts process simulation results

When vehicle gear in 3 files, you can proceed to change down the process of simulation, downshifts process simulation results as shown in figure 3.In addition, through the experiment, the transmission time delay is set to 3 seconds, can avoid vehicles frequently shift, and in the case of the speed change, keep the transmission will be on shift operation of turbine high power output.So, by implementing energy-saving shift operation of engineering vehicles, can improve the performance and fuel economy of vehicles.

\section{Conclusion}

Aimed at the problem of low efficiency of construction vehicle hydraulic torque converter, this paper puts forward a kind of high efficiency and energy saving shift schedule, and in the Matlab/Simulink simulation environment for simulation study of the law, so as to verify the correctness of the proposed law.And the use of the law can not only improve the power performance of vehicle transmission system, can improve the efficiency of the vehicle.As a result, the shift schedule is proposed, to promote the development of our country the application of engineering vehicles has a certain theoretical significance and application value.

\section{References}

[1] Ye Dan.Engineering vehicles three parameters automatic transmission theory research[D].Jilin university,2004.

[2] Xing WenJin,Yang Baokun.Research status of domestic automatic transmission shift schedule review[J]. Journal of equipment manufacturing technology,2014.

[3] $\mathrm{Wu}$ Guangqiang,Sun Xianan.Automobile automatic transmission developmentreview[J]. Journal of tongji university(natural science edition),2010,38(10).

[4] Huang Yongjing,Yao Jin,Han Jiahua. Construction vehicle automatic transmission technology and research development[J].Journal of coal mine machinery,2013. 
[5] Tang Yongqi.Pure electric automobile automatic transmission shift schedule study[J].Journal of hefei university journal(natural science edition),2012,65:60-65.

[6] Chengyuan Wang.Widened. Motor control technology [M]. Beijing:China machine press, 2006.

[7] Zhao Xinxin,Zhang Wenming,Feng Yali etc.Construction vehicle automatic transmission shift process modeling and simulation[J].Journal of huazhong university

of science and technology (natural science edition),01 2014:2014-116. 